\section{Smart-card traffic system keeps Singapore in the fast lane}

Sir - Recognizing the high economic and environmental costs of traffic gridlocks, Singapore recently implemented an electronic road pricing (ERP) system, the first of its kind in the world. Using a network of overhead gantries straddling the central business district and the approach routes and expressways leading there, the system works by remotely debiting tariffs from a smart card installed in a slot near the vehicle's windscreen. Infringement is registered by capturing the image of the vehicle's number plate. Our experience of this system, phased in during 1998 and 1999, offers some perspectives to other regions contemplating the use of this technology to manage congestion.

A major barrier to the implementation of electronic tolling is public aversion to infringement of privacy. In the passive electronic toll systems used in some parts of Australia, Canada, Europe and the United States, vehicles need to be tagged and their movements monitored for monthly billing. Singapore instead chose the cash-card system, in which direct debiting removes the need for billing and debt collection.

There needs to be political courage in implementing congestion tolls. Singapore ran a public education campaign to show that ERP is about reducing vehicle usage, not making money. Indeed, revenue has plunged by about $40 \%$ compared with the previous, manual tolling system, since fewer drivers use the tolled roads. The government absorbed the cost of fitting every vehicle in Singapore with a unit for cash cards, gave road-tax rebates and reduced customs and registration costs for new cars, so motorists saved money. This has helped public acceptance of ERP.

There is a limit to how far civil engineering can enhance road capacity in urban areas, faced with an ever-increasing number of vehicles. A congestion toll by ERP helps to price roads as scarce commodities and therefore promotes their efficient use, besides being more costeffective than a 'manual toll plaza', or series of toll booths, where motorists have to stop and pay. The Singapore system has several advantages: there is no need for vehicles to stop or slow down as they pass the gantry; it lets large numbers of vehicles through; it allows toll charges to be incorporated based on the vehicle class; and it eliminates cash handling, thus enhancing commuter convenience and revenue security.

For expressways and approach routes leading to the city, a tiered pricing scheme operates during the peak period from 7.30 a.m. to 9.30 a.m. on weekdays. For roads in the central business district, another pricing scheme operates from 7.30 a.m. to 7 p.m. The system has allowed various pricing schemes to be tested, so that optimal speed levels are achieved on expressways (45-65 km per hour) and roads in the central business district (20-30 km per hour) by reducing the number of vehicles using tolled roads during peak hours.

Unlike the previous system, under which daily or monthly permits allowed an unlimited number of journeys, the present pay-per-trip mechanism discourages extra car use. The system motivates drivers to try quieter roads, use public transport or car-sharing schemes, and drive in off-peak periods where possible. The ERP experiment is currently being monitored before extending it to more freeways in Singapore.

Leo Tan Wee Hin, R. Subramaniam

Singapore National Academy of Science, 15 Science Centre Road, Singapore 609081

\section{Mathematical model could clarify arms race}

Sir - The US government's recent decision to enlarge its missile-defence systems, and the response of other countries in Asia which have perceived this as a threatening move, raise the question of whether a new global arms race is beginning. Mathematical models about the relationship between armaments and conflict need to be discussed openly by scientists, ideally in a structured context similar to the way in which climate-change models are discussed, to help governments make the most appropriate strategic decisions.

Lewis Fry Richardson developed a simple model of coupled differential equations to show how expenditure on armaments by antagonistic nations had grown exponentially before the First and Second World Wars. This led him to predict — in a letter beginning "As Nature has encouraged scientific workers to think about public affairs ..." (Nature 135, 830; 1935) — that there would be a second world war when the armaments of both sides became dangerously numerous. War could be avoided, he warned, only if the leaders of the arming countries took immediate and decisive action.

By 1951, Richardson had developed and refined his model, and Nature published his letter (Nature 168, 567-568; 1951) in which he asked whether the third major arms race of the twentieth century would also inevitably lead to a world war.
In some respects his refined model predicted the ending of the US-Soviet cold war, though it has been argued that his equations do not strictly allow such an interpretation (see I. Sutherland, Collected Papers of Lewis Fry Richardson Vol. 2, Cambridge University Press, 1993).

Most countries reduced their stock of armaments during the 'new world order' period between 1989 and 1999, with the exception of China and India. The question now is what kind of prediction would result from conflict/armament models such as Richardson's when applied to the present situation. As things stand, the model equations tend to show great sensitivity to small variations in relative armaments at this critical stage, so much work is needed. It is to be hoped that concerned "scientific workers" and others are convinced that the present international situation is potentially serious, and that every relevant method should be applied to the prediction of events and the exploration of constructive strategies.

Political analyses are necessary, but are not a complete substitute for scientifically based quantitative and probabilistic evaluations of complex outcomes and possible remedial actions.

Nowadays, when governments are more open about their use of mathematical models for systems such as the economy, climate change and spread of disease, it could be argued that they should also be open about how they are applying mathematical models to the international strategic situation. Those models would be more effective in influencing events if they were widely applied and accepted, especially in countries where crucial political and defence decisions are now being considered.

\section{J. C. R. Hunt}

Department of Space \& Climate Physics, University College London, Gower Street, London WC1E 6BT, UK

\section{More light shed on the Mauna Kea controversy}

Sir - Your News report "Astronomers bargain for use of 'sacred' site" (Nature 410, 1015; 2001) was an excellent overview of the cultural dimensions of the controversy on Mauna Kea, Hawaii. However, your story did not mention two other key issues fuelling local animosity towards the observatories - past mismanagement and proposals to limit public access.

In 1998, a legislative audit concluded that, during its 30-year tenure on Mauna Kea, the University of Hawaii's Institute for Astronomy (together with the state's land 
board) had "failed to develop and implement adequate controls to balance the environmental concerns with astronomy development". The audit also confirmed islanders' charges of broken promises, violated leases and ignoring of environmental laws.

After the audit, the university's president and the Institute for Astronomy blamed the public for problems on the mountain top, and proposed access restrictions that were later included in the university's second, flawed master plan, discussed in your report. All this has made the islanders even more upset.

Given this history, the quote by NASA's Keck programme manager, John Lee, that the organization does not want to "poison the well" for astronomy on Mauna Kea, seems ironic to many islanders. NASA and the international astronomy community need to understand that those 'toxins' were introduced by the Institute for Astronomy and the observatories, and will have to be removed by them before anything else is built on the mountain.

Nelson Ho

Hawaii Chapter of Sierra Club, 32 Kahoa St Hilo, Hawaii 96720-2206, USA

\section{A new approach to global book distribution}

Sir - As pointed out by Keese in Correspondence (Nature 410, 1021; 2001) and in your current web debate (http:// www.nature.com/nature/debates/ e-access/index.html), lack of access to scientific information is a widespread problem. I have experimented with a means for obtaining free books and distributing them to individuals and libraries, and believe this technique could be widely used.

The cost of extending print runs to produce extra copies of books is reasonably small — comparable to typical royalties. When I completed a conservation textbook for Blackwell Scientific, the publisher agreed to my suggestion that, in lieu of royalties, it would provide me with a free copy for each one sold. My aim was to send the book out to practising conservationists who would otherwise be unlikely to obtain it. The online bookshop nhbs.com (http://www.nhbs.com) offered to coordinate the distribution, and the Christensen Fund kindly paid for the postage.

As this scheme became known, we received many requests and suggestions for recipients (we welcome further suggestions — please contact me at w.sutherland @uea.ac.uk). Within a few months of publication we were able to send out more than 1,250 copies of the book to people in 126 developing countries.

Such schemes could be widely applied to scientific and technical books, and everyone will benefit if the following three suggestions are followed. First, authors could ask publishers to provide all or some of their royalties in the form of extra copies. Authors write to be read, and this procedure greatly increases the distribution and hence the readership of a book. Second, academic societies and grantawarding bodies could allocate funds for posting books, a very cost-effective means of promoting a subject. The distribution could be carried out at cost price, organized either through an academic body, through the author's institution or through a commercial organization. The distributor can gain some excellent publicity by doing this. Third, publishers could advertise the fact that they are happy to proceed with such arrangements.

The charity Book Aid International (www.bookaid.org; info@bookaid.org) has also expressed an interest in distributing suitable books through its network.

The scheme offers clear advantages to publishers, as it improves their image and may attract authors. In the current case, the publisher believes the offer has increased sales.

\section{William J. Sutherland}

School of Biological Sciences, University of East Anglia, Norwich NR4 7TJ, UK

\section{Improving taxonomy for us and the other fishes}

Sir - Lewin in his engaging Concepts essay (Nature 410, 637; 2001) asserts that unless "demanded by expediency", recent changes in taxonomy "muddle our language, and could introduce confusion in our libraries". Two of his examples involve traditional groups that are unambiguously paraphyletic (each of them includes an ancestor but not all of its descendants), and they nicely illustrate why monophyletic taxa (those comprised of a common ancestor and all of its descendants) are preferable for teaching, research and influencing public attitudes towards nature.

Lewin claims that molecular phylogenetics has led to "a host of new problems": for example, "Because crocodiles are believed to be more closely related to birds than they are to turtles ... are sparrows just feathered reptiles, and does ornithology become merely a branch of herpetology?". That birds and crocodiles are each other's closest living relatives was a consensus view long before the advent of
DNA sequencing, as has the conclusion that reptiles (including birds) are more closely related to mammals than they are to amphibians. Herpetology, defined monophyletically as the biology of tetrapods, thus does incorporate mammalogy and ornithology, but this no more makes sparrows "just" feathered reptiles than it reduces bats to "just" winged mammals; ornithology is no more "merely" a branch of herpetology than the latter is "merely" a part of vertebrate biology.

More important, traditional failure to taxonomically formalize a close relationship between crocodilians and birds obscures their similarities in parental care, acoustic communication and various internal traits. Perhaps that failure also explains why some recent analyses of life-history evolution in each group fail to cite work on the other, and why they also ignore a substantial literature on reproduction in closely related, extinct archosaurs.

Lewin correctly notes that the coelacanth Latimeria "is closer to humans than it is to herrings", but then complains, "so what price ichthyology?". Actually, the incredible panoply of fishes is done an injustice by traditional recognition of two basal taxa, one of them spectacularly successful (there are more than 20,000 species of ray-fins) and the other usually viewed as an evolutionary dead-end (Latimeria and lung-fishes).

A monophyletic perspective enriches ichthyology by, instead, emphasizing that the adaptive radiation of fishes includes two more-or-less equally speciose subclades, one largely confined to water (the ray-fins) and the other represented by both aquatic and terrestrial forms (coelacanths, lung-fishes, tetrapods).

Of course, one could argue that tetrapods are special because they move about on land and have changed a lot, but then so have walking catfish, swamp eels and mudskippers, all of which we appropriately leave in with other ray-finned fishes.

Lewin disapproves of new names and altered meanings for old names, whereas my experience is that students are inspired by the underlying rationale for such changes. Lay people likewise are intrigued by behavioural similarities between crocodilians and birds, and amused by the realization that we are all fishes. Rather than hindering biology, increasingly accurate and phylogenetically based taxonomy promotes the study and appreciation of life's diversity.

\section{Harry W. Greene}

Department of Ecology and Evolutionary

Biology, Cornell University, Ithaca,

New York 14853-2701, USA 